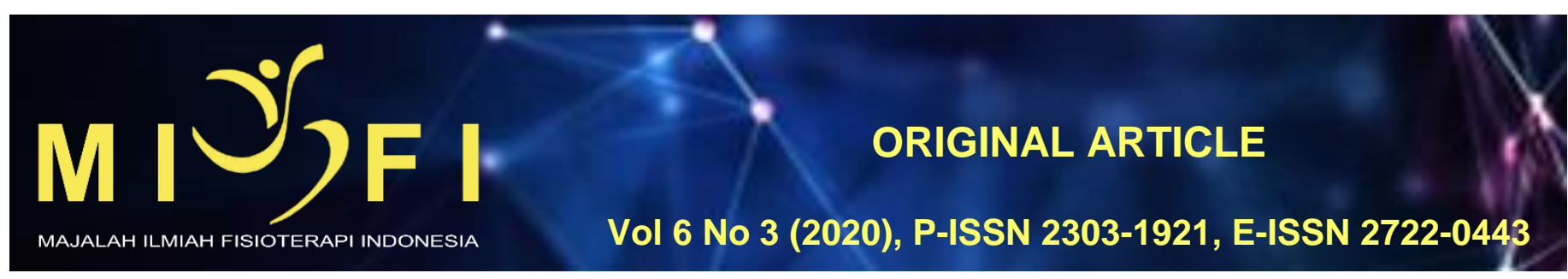

\title{
HUBUNGAN ANTARA DURASI DUDUK DAN POSISI DUDUK DENGAN FLEKSIBILITAS OTOT HAMSTRING PADA PEGAWAI KANTOR INSTANSI PEMERINTAH SEWAKA DHARMA KOTA DENPASAR
}

\author{
Putri Miucin ${ }^{1}$, Anak Ayu Nyoman Trisna Narta Dewi ${ }^{2}$, Luh Putu Ratna Sundari ${ }^{3}$, I Wayan Sugiritama ${ }^{4}$ \\ ${ }_{1}^{1}$ Program Studi Sarjana Fisioterapi dan Profesi Fisioterapi, Fakultas Kedokteran Universitas Udayana, Denpasar,Bali \\ ${ }^{2}$ Departemen Fisioterapi, Fakultas Kedokteran Universitas Udayana, Denpasar,Bali \\ ${ }^{3}$ Departemen IImu Faal, Fakultas Kedokteran Universitas Udayana, Denpasar,Bali \\ ${ }^{4}$ Departemen Histologi, Fakultas Kedokteran Universitas Udayana, Denpasar,Bali \\ Putrimiucin@gmail.com
}

\begin{abstract}
ABSTRAK
Gerakan fungsional sering mengalami gangguan yang mengakibatkan terjadinya keterbatasan dalam bergerak. Hal tersebut dapat diakibatkan oleh beberapa faktor dan penyebab salah satu terganggunya komponen biomotorik yaitu fleksibilitas pada otot hamstring. Faktor pemicu utamanya adalah durasi duduk dan posisi duduk saat bekerja. Desain penelitian ini yaitu analitik cross sectional. Jumlah sampel sebanyak 67 orang pekerja laki-laki dan perempuan yang berusia 35- 55 tahun. Variabel bebas yang diukur adalah durasi duduk dan posisi duduk sedangkan variabel terikatnya yaitu fleksibilitas otot hamstring. Hasil penelitian menunjukkan bahwa durasi duduk dan posisi duduk memiliki hubungan yang signifikan dengan risiko terjadinya penurunan fleksibilitas otot hamstring $(p<0,05)$. Kesimpulan dari penelitian ini yaitu semakin lama dan semakin tinggi resiko posisi duduk semakin rendah fleksibilitas otot hamstring pada pegawai kantor.
\end{abstract}

Kata Kunci: durasi, posisi, fleksibilitas

\section{RELATIONSHIP BETWEEN DURATION OF SITTING AND POSITION SITTING WITH FLEXIBILITY OF MUSCLE HAMSTRING IN GOVERNMENT INSTITUTION OFFICE OF SEWAKA DHARMA KOTA DENPASAR}

\section{ABSTRACT}

Human has a primary obligation survive his live by affording daily necessities, therefore human must to work. Some jobs obliged their employee to sit all day long, especially in this advancement era of technology. Instantly, many jobs can be done by machine, such as computer and online services. This affect to reduce physical activity and intention to have some exercises that can cause a high risk of injury, for instance employees at Sewaka Dharma government institution in Denpasar. Their jobs demand them to sit all day long as called as white-color worker, known as jobs that demand their employee to be seated all day long as they work using their brains more than any of their physical efforts and usually being done on a working desk or work station. Employees in service sector are obliged to work in sitting position for a long time as long as seven to eight hours. One of the muscles that taking role in sitting position is hamstring muscle. Hamstring muscle is having a tendency to get tighten. The tightness of hamstring muscle can be caused by the duration of sitting position in constant moment. The effect of this tightness is reducing hamstring muscle's flexibility and lead to the limitation of functional motion

Keywords : Duration, Position, Flexibility

\section{PENDAHULUAN}

Manusia memiliki kewajiban untuk mempertahankan hidupnya dengan cara memenuhi kebutuhan seharisehari, namun untuk memenuhi kebutuhannya manusia dituntut untuk bekerja. Sebagian pekerjaan menuntut para pekerjanya untuk bekerja dengan posisi duduk, terlebih pada jaman serba canggih ini, semua serba instan banyak pekerjaan yang dapat dilakukan oleh mesin contohnya komputer dan adanya jasa online, hal tersebut menyebabkan menurunnya aktivitas fisik dan kesadaran untuk berolahraga yang akan meningkatkan resiko cedera, salah satunya pada pegawai kantor di instansi pemerintahan sewaka dharma kota Denpasar. Tuntutan pekerjaan yang mengharuskan para pekerja nya bekerja dengan posisi duduk juga disebut white-color worker yaitu pekerja yang banyak menggunakan daya pikiran dalam melakukan pekerjaan dan dilakukan dalam sebuah workstation yang biasanya berupa sebuah meja kerja dan kursi. Pekerja kantor pada bidang pelayanan dituntut untuk bekerja dengan posisi duduk dengan durasi yang lama. Pekerja kantor melakukan pekerjaannya dalam durasi 7-8 jam. Salah satu otot yang berperan dalam posisi duduk ialah otot hamstring. Otot hamstring memiliki kecendrungan untuk memendek. Pemendekan otot hamstring tersebut dapat disebabkan karena durasi duduk dan posisi duduk pada pegawai kantor yang terjadi terus menerus. Dampak dari pemendekan otot hamstring yaitu penurunan fleksibilitas otot hamstring yang akan menghasilkan keterbatasan gerak fungsional.1

Fleksibilitas adalah kemampuan otot untuk mengulur atau memanjang yang di dasari oleh luasnya gerakan pada sendi hal tersebut berhubungan juga dengan kemampuan peregangan otot dan jaringan di sekeliling sendi sehingga otot dapat bergerak dengan Range of Motion (ROM) yang maksimal tanpa disertai dengan rasa tidak nyaman atau nyeri.12 Penelitian yang dilakukan pada kelompok umur 17-23 tahun memiliki kecendrungan pemendekan otot 
hamstring yang dapat terjadi jika seseorang duduk dengan durasi 6-8jam dengan posisi hip dan knee fleksi $90^{\circ}$ yang berpengaruh terhadap terjadinya cedera pada otot hamstring yaitu pemendekan otot hamstring. Pemendekan otot hamstring diakibatkan oleh gerakan statis yang terus menerus.7

Faktor - Faktor yang mempengaruhi fleksibilitas dapat dibagi menjadi dua yaitu faktor eksternal dan faktor internal. Faktor internal yang dapat mempengaruhi fleksibilitas yaitu jenis sendi, struktur tulang, elastisitas jaringan, tendon, dan ligament, kemampuan otot untuk rileks dan berkontraksi untuk mencapai kisaran terbesar dari gerakan, suhu jaringan sendi sedangkan faktor eksternal yang mempengaruhi adalah suhu suatu tempat tersebut. Suhu yang cenderung hangat lebih kondusif dalam peningkatan fleksibilitas sedangkan pada suhu yang lebih dingin fleksibilitas akan menurun. Faktor resiko yang dapat menyebabkan terjadinya penurunan fleksibilitas otot hamstring yaitu posisi duduk yang salah dan cendrung statis dengan durasi yang lama.1

Penurunan fleksibilitas otot hamstring yang dapat terjadi akibat kebiasaan bekerja dengan posisi duduk dengan durasi yang lama tidak menutup kemungkinan dapat dialami oleh pekerja di Kota Denpasar salah satu nya di Instansi Pemerintah Sewaka Dharma Kota Denpasar Oleh karena itu diperlukan tindakan antisipasi untuk mencegah terjadinya penurunan fleksibilitas otot hamstring. Tindakan antisipasi yang dapat dilakukan yaitu dengan meneliti lebih lanjut hubungan antara durasi duduk dan posisi duduk dengan fleksibilitas otot hamstring pada pegawai kantor Instansi Pemerintah Sewaka Dharma Kota Denpasar.

\section{METODE}

Desain penelitian ini menggunakan rancangan observasi analitikCross Sectional yang dilakukan pada kantor Instansi Pemerintah Sewaka Dharma Kota Denpasar. Penelitian dilakukan pada bulan April. Jumlah sampel pada penelitian ini yaitu 67 orang pekerja. Sampel dipilih menggunakan teknik pengambilan Purposive Sampling dan memenuhi kriteria inklusi dan eksklusi diantaranya berusia 35-55 tahun, bekerja dengan posisi duduk berdurasi lebih dari 6 jam, tidak mengalami cedera pada otot hamstring ataupun tidakmenggunakan alat bantu berjalan.

Durasi duduk dan posisi duduk merupakan variabel bebas sedangkan fleksibilitas otot hamstring merupakan variabel terikat. Metode rapid entire body assessment (REBA) digunakan untuk mengukur risiko posisi duduk dengan interpretasi dapat diabaikan (skor REBA 1), resiko kecil (skor REBA 2-3), resiko sedang (skor REBA 4-7), resiko tinggi (skor REBA 8-10), resiko sangat tinggi (skor REBA >11). Durasi duduk diukur menggunakan kuesioner IPAQ SF Prsentase ini ditentukan dari total jam kerja dalam satu hari. Fleksibilitas otot hamstring diukur menggunakan metode sit and reach test dengan interpretasi sangat bagus, bagus, sedang, kurang, sangat kurang.

Data yang telah dikumpulkan kemudian diuji kenormalan persebarannya menggunakan uji Kolmogorov Smirnov. Uji Spearman's Rho digunakan untuk mengetahui signifikansi, kekuatan dan arah hubungan antara durasi duduk dan posisi duduk dengan fleksibilitas otot hamstring pada pegawai kantor. Uji Regresi linier ganda digunakan untuk mengetahui besar pengaruh dan kuat hubungan antara variabel bebas dan variabel terikat.

\section{HASIL}

Tabel 1. Karakteristik sampel berdasarkanusia, jenis kelamin, durasi duduk, dan posisi duduk.

\begin{tabular}{ccc}
\hline Variabel & Frekuensi (f) & Presentase (\%) \\
\hline Kelompok Usia & & \\
35-40 tahun & 27 & 40,3 \\
$41-45$ tahun & 16 & 23,9 \\
$46-50$ tahun & 14 & 20,9 \\
$51-55$ tahun & 10 & 14,9 \\
Durasi Duduk & & \\
7 jam & 11 & 16.4 \\
8 jam & 10 & 14,9 \\
9 jam & 5 & 7,5 \\
10 jam & 15 & 22,4 \\
11 jam & 20 & 29,9 \\
12 jam & 5 & 7,5 \\
14 jam & 1 & 1,5 \\
Jenis Kelamin & & \\
Laki-Laki & 32 & 47,8 \\
Perempuan & 35 & 52,2 \\
Posisi Duduk & & \\
Sedang & 59 & 88,1 \\
Tinggi & 8 & 11,9 \\
\hline
\end{tabular}

Berdasarkan Tabel 1. di atas, dari 67 sampel, terdapat frekuensi pegawai kantor di Instansi Pemerintah Sewaka Dharma Kota Denpasar pada kelompok usia 35-40 tahun sebanyak 27 orang $(40,3 \%)$, usia 41-45 tahun sebanyak 16 orang $(23,9 \%)$, usia $46-50$ tahun sebanyak 14 orang (20,9\%), usia 51-55 tahun sebanyak 10 orang (14,9\%). Pada pegawai kantor durasi kerja 7 jam sebanyak 11 orang $(15,4 \%)$, durasi kerja 8 jam sebanyak 10 orang (14,9\%), durasi kerja 9 jam sebanyak 5 orang $(7,5 \%)$, durasi kerja 10 jam sebanyak 15 orang $(22,4 \%)$, durasi kerja 11 jam sebanyak 20 orang $(29,9 \%)$, durasi kerja 12 jam sebanyak 5 orang $(7,5 \%)$, durasi kerja 14 jam sebanyak 1 orang $(1,5 \%)$. Pada jenis kelamin laki-laki sebanyak 32 orang $(47,8 \%)$, dan jenis kelamin perempuan sebanyak 35 orang (52,2\%). Pada penelitian ini, yang digunakan mengukur posisi duduk yaitu skor REBA pada pegawai kantor di Instansi Pemerintah 
sewaka Dharm berjumlah 67 orang dan dibagi ke dalam kelompok skor REBA. Berikut adalah karakteristik skor REBA dengan risiko sedang sebanyak 59 orang $(88,1 \%)$, dan risiko tinggi sebanyak 8 orang $(11,9 \%)$.

Tabel 2. Hubungan Durasi Duduk Dengan Fleksibilitas Otot Hamstring

\begin{tabular}{ccc}
\hline Korelasi Variabel & Rs & p \\
\hline Durasi duduk dengan & $-0,637$ & 0,000 \\
Fleksibilitas otot hamstring & &
\end{tabular}

Berdasarkan Tabel 2. menunjukkan bahwa terdapat hubungan bermakna antara durasi duduk dengan fleksibilitas otot hamstring $(p<0,05)$ dengan koefisien korelasi sebesar $-0,637$ hal ini berarti bahwa terdapat hubungan yang kuat, signifikan, dan berlawanan arah antara posisi duduk dengan fleksibilitas otot hamstring pada pegawai kantor di Instansi Pemerintah Sewaka Dharma Kota Denpasar

Tabel 3. Hubungan Posisi Duduk Dengan Fleksibilitas Otot Hamstring

\begin{tabular}{ccc}
\hline Korelasi Variabel & Rs & $\mathbf{p}$ \\
\hline $\begin{array}{c}\text { Posisi duduk dengan } \\
\text { Fleksibilitas otot hamstring }\end{array}$ & $-0,257$ & 0,036 \\
\hline
\end{tabular}

Berdasarkan Tabel 3. menunjukkan bahwa terdapat hubungan bermakna negatif antara posisi duduk dengan fleksibiltas otot hamstring yaitu $p=0,036$ atau $(p<0,05)$ dengan koefisien korelasi sebesar $-0,257$. Hal ini berarti bahwa terdapat hubungan yang kuat, signifikan, dan berlawanan arah antara posisi duduk dengan fleksibilitas otot hamstring pada pegawai kantor di Instansi Pemerintah Sewaka Dharma Kota Denpasar .

Tabel 4. Hubungan Durasi Duduk dan Posisi Duduk Terhadap Fleksibilitas Otot Hamstring

\begin{tabular}{ccccc}
\hline Regresi Variabel & $\mathbf{R}$ & F Hitung & F Tabel & p \\
\hline Durasi duduk dan posisi duduk dengan fleksibilitas otot hamstring & 0,755 & 42.406 & 2,74 & 0,000 \\
\hline
\end{tabular}

a. Variabel Dependen : Sit and Reach Test

Berdasarkan Tabel 4 menunjukkan bahwa terdapat hubungan antara durasi duduk, posisi duduk dengan fleksibilitas otot hamstring dengan $F$ hitung $>F$ table $(42.406>2,74)$ atau $p<0,05)$. Korelasi $(R)$ yang secara simultan (bersama-sama) antara variabel durasi duduk, posisi duduk dengan fleksibilitas otot hamstring. Diperoleh nilai sebesar 0,755 .

Tabel 5. Hasil Analisis Multivariat Durasi Duduk dan Posisi Duduk Terhadap Fleksibilitas Otot Hamstring

\begin{tabular}{|c|c|c|c|c|c|}
\hline Variabel & B & Std. Error & T Hitung & $\mathbf{P}$ & T tabel \\
\hline Durasi Duduk & 1,007 & 117 & -8.607 & 0,000 & 1,667 \\
\hline Posisi Duduk & 909 & 240 & $-3,786$ & 0,000 & \\
\hline
\end{tabular}

a. Variabel Dependen : Fleksibilitas otot hamstring

Berdasarkan Tabel 5. menunjukkan seberapa besar pengaruh variabel Independent terhadap variabel dependent yaitu fleksibilitas otot hamstring dapat diprediksi dengan peningkatan durasi duduk 1,007 dengan nilai T hitung $>\mathrm{T}$ table $(8,607>1,667)$ atau $\mathrm{p}<0,05$, akan menurunkan fleksibilitas otot hamstring dan semakin tinggi nilai reba atau skor posisi duduk akan menurunkan fleksibilitas otot hamstring $T$ hitung $>T$ tabel $(3,786>1,667)$ atau $p<0,000$ dan didapatkan simpulan semakin tinggi durasi duuk semakin rendah skor fleksibilitas otot hamstringnya dan semakin tinggi skor yang didapatkan saat pengukuran posisi duduk demakin rendah skor fleksibilitas otot hamstring pada pegawai kantor Instansi Pemerintah Sewaka Dharma Kota Denpasar.

\section{DISKUSI}

\section{Karakteristik Sampel Penelitian}

Hasil penelitian menunjukkan sampel berjumlah 67 orang pekerja yang berjenis kelamin laki-laki dan perempuan dengan persebaran usia 35- 55 tahun. Hal tersebut sesuai dengan penelitian sebelumnya yaitu durasi duduk yang cukup lama dalam 6-8 jam terhadap pemendekan otot hamstring. Pemendekan otot hamstring dikaitkan dengan pola kontrol motorik disfungsional yang mengarah ke pola sub-maksimal otot postural yang menghasilkan fungsi hamstring sebagai penstabil dari pada fungsi utama penggerak utama. Perubahan fungsi primer ini menyebabkan adanya penekanan pada hamstring. Jam kerja yang berkepanjangan yang dibutuhkan di sebagian besar pekerjaan dapat mempengaruhi jaringan lunak terutama pada otot dan sendi. ${ }^{9}$

Distribusi responden berdasarkan posisi duduk menunjukkan bahwa posisi duduk yang mengalami resiko sedang dengan rentang skor REBA 4-7 yang artinya level resiko terjadinya penurunan fleksibilitas otot hamstring tindakannya perlu dilakukan perubahan atau perbaikan posisi duduk. Kemudian, posisi duduk pegawai yang mengalami resiko tinggi dengan rentang skor REBA 8-10 yang artinya level resiko penurunan fleksibilitas otot hamstring tindakannya perlu dilakukan perbaikan dan perubahan posisi duduk segera. Hasil penelitian ini juga didukung oleh pernyataan dari Page et al (2010) pada saat duduk posisi Pelvis berputar kearah belakang, yang menyebabkan peningkatan tension pada otot hamstring dan gluteal sehingga otot tersebut mengalami tigthness dan mengakibatkan fleksibilitasnya terganggu.

\section{Hubungan Durasi Duduk Dengan Fleksibilitas Otot Hamstring}

Hasil analisis data menunjukkan bahwa durasi duduk memiliki hubungan yang signifikan dengan risiko terjadinya penurunan fleksibilitas otot hamstring Hasil tersebut berarti $p<0,05$ yang menunjukkan bahwa ada hubungan signifikan antara durasi duduk dan fleksibilitas otot hamstring pada pegawai kantor sehingga terdapat keeratan hubungan antara kedua variabel kuat. Tanda korelasi negatif memiliki makna bahwa kedua variabel memiliki arah hubungan yang berpola tidak searah, hal ini dapat diartikan bahwa semakin lama durasi duduk pegawai maka semakin rendah skor fleksibilitas 
otot hamstring nya, begitu juga sebaliknya semakin rendah durasi duduk pada pegawai semakin tinggi skor fleksibilitas otot hamstringnya.

Penelitian ini sesuai dengan penelitian yang dilakukan pada pegawai kantor frekuensi penurunan fleksibilitas otot hamstring pada pegawai kantor bahwa durasi duduk yang berkepanjangan (6-8 jam) setiap harinya berkaitan dengan penurunan fleksibilitas otot hamstring dimana pada penelitian tersebut menyebutkan adanya gangguan aktivitas fungsional pada pegawai kantor sehingga dapat menurunkan konsentrasi saat bekerja. ${ }^{30}$ Penelitian ini juga didukung oleh penelitian sebelumnya yaitu hamstring tightness dikaitkan dengan pola kontrol motorik disfungsional yang mengarah ke pola sub-maksimal otot postural yang menghasilkan fungsi hamstring sebagai penstabil dari pada fungsi utama penggerak utama mereka. Perubahan ungsi primer ini menyebabkan adanya penekanan hamstring. Jam kerja berkepanjangan yang dibutuhkan di sebagian besar pekerjaan dapat mempengaruhi jaringan lunak yaitu otot. Serta dengan menggunakan metode sit and reach test untuk mengetahui skor fleksibilitas otot hamstring. ${ }^{9}$

\section{Hubungan Posisi Duduk Dengan Fleksibilitas Otot Hamstring}

Berdasarkan uji analisis korelasi posisi duduk dengan fleksibilitas otot hamstring dapat diketahui menggunakan uji statistik Spearman's Rho yang tertera pada tabel 5.7 pada tabel tersebut dapat dilihat hasil dari uji spearman's rho sebesar $R s=-0,257$ dengan nilai $P=0,036$ Hasil tersebut berarti $p<0,05$ yang menunjukkan bahwa ada hubungan signifikan antara posisi duduk dengan fleksibilitas otot hamstring pada pegawai kantor sehingga terdapat keeratan hubungan antara kedua variabel kuat. Tanda korelasi negatif memiliki makna bahwa kedua variabel memiliki arah hubungan yang berpola tidak searah, hal ini dapat diartikan bahwa semakin tinggi skor REBA dalam resiko posisi duduk pada pegawai kantor maka semakin rendah skor fleksibilitas otot hamstring nya, begitu juga sebaliknya semakin rendah skor REBA dalam posisi duduk pada pegawai kantor semakin tinggi skor fleksibilitas otot hamstringnyaPada penelitian sebelumnya menyebutkan posisi duduk yang cendrung statis dalam waktu yang lama akan menyebabkan hamstring tightness dan jika hal tersebut berlangsung lama akan menyebabkan penurunan fleksibilitas otot hamstring. ${ }^{20} \mathrm{Gangguan}$ fungsi postural sangat berkaitan dengan Postural Habits, maksudnya keadaan postur dalam rutinitas individu dikesehariannya. ${ }^{15}$ Posisi duduk yang cendrung statis akan menyebabkan penekanan pada otot hamstring. Distribusi darah merupakan jalur asupan energi disetiap komponen jaringan, sehingga apabila terganggu akan menyebakan beberapa respon fisiologis otot yang ikut terganggu, seperti proses kontraksi dan relaksasi pada otot. Kontraksi dan relaksasi otot tidak lepas dari peran actin dan myosin sebagai bagian dari sarkomer yang berfungsi sebagai jaringan kontraktil pada tubuh manusia. Terjadinya respon anatara actin dan myosin tersebut membutuhkan energi cepat sebagai bahan dasar utama timbulnya suatu respon kontraksi dan relaksasi. Namun pada hal ini kebutuhan energi tersebut tidak dapat terpenuhi akibat adanya gangguan sirkulasi darah kapiler dalam jaringan sehingga respon kontraksi dan relaksasi pada actin dan myosin ikut terganggu, gangguan tersebut berupa terjadinya cross linked pada actin dan myosin. ${ }^{15}$

Jaringan elastin yang terganggu tersebut sangat berkaitan dengan Muscle Spindel dan Golgi Tendon Organ yang berfungsi sebagai Strech Reseptor pada jaringan kontraktil. Ketika terjadinya perubahan atau kerusakan pada komponen struktur elastin, akibat level kerja otot dalam posisi statis, maka hal tersebut akan memberikan dampak signal yang akan direspon oleh muscle strain sebagai perubahan panjang pada otot, lalu muscle strain akan beradaptasi dengan kondisi otot yang berkontraksi secara statis. Kondisi adaptasi yang dilakukan oleh muscle strain akan memberikan rambatan signal kepada golgi tendon yang berfungsi sebagai pendeteksi ketegangan (muscle tension) selama kontraksi otot atau peregangan otot. Ketegangan (tightness) yang terjadi jika terlalu lama akan menimbulkan efek yang tidak baik bagi jaringan kontraktil. Efeknya jaringan kontraktil tersebut akan mengalami pemendekan (shortness), sehingga akan berdampak terhadap fleksibilitas otot hamstring. ${ }^{15}$

\section{Hubungan Durasi Duduk dan Posisi Duduk Dengan Fleksibilitas Otot Hamstring.}

Pada penelitian ini, hubungan durasi duduk dan posisi duduk dengan fleksibilitas otot hamstring pada pegawai kantor dapat diketahui dengan menggunakan metode uji statistic regresi linier ganda tujuan dari analisis tersebut yaitu untuk mengetahui seberapa besar pengaruh dari variabel bebas dengan variabel terikat. Hasil analisis regresi linier ganda durasi duduk dan posisi duduk dengan fleksibilitas otot hamstring menunjukkan bahwa fleksibilitas otot hamstring dapat diprediksi dengan peningkatan durasi duduk 1,007 dengan nilai T hitung $>$ T table $(8,607>1,667)$ atau $p<0,05$, akan menurunkan fleksibilitas otot hamstring dan semakin tinggi nilai reba atau skor posisi duduk akan menurunkan fleksibilitas otot hamstring $T$ hitung $>T$ tabel $(3,786>1,667)$ atau $p=0,000$. Hal ini sesuai dengan penelitian yang dilakukan oleh Pramasita tahun 2016 dimana seseorang memiliki kebiasaan duduk yang cendrung statis berulang dengan durasi duduk 6- 8 jam dalam sehari dapat menyebabkan otot-otot hamstring beradaptasi dengan keadaan memendek atau tight Biomekanik posisi duduk pada pegawai yaitu posisi pelvic berputar kearah posterior atau posterior pelvic tilting akibat flatt-nya kurva vertebra lumbal maka terjadi perubahan tensitas pada otot hamstring. Perubahan tersebut akan mengakibatkan aktivitas kinerja otot yang overload. ${ }^{29}$ Apabila kinerja otot mengalami overload dalam waktu yang lama pada motor unit (prolonged motor task) maka akan membuat penumpukan sisa metabolic, yang akan menyebabkan gangguan homeostasis ion kalsium dalam sel otot, Kondisi ini akan menyebabkan terjadinya kerusakan autogenic pada membran sel otot. Kerusakan membran ini menyebabkan kebocoran intraselular enzim laktat dehidrogenase, kerusakan mitokondria sel otot, dan kekurangan energi pada sel otot dan menghasilkan nyeri karena pelepasan IL-6 dan cytokines lainnya yang pada akhirnya menyebabkan kerusakan struktur myofilamen pada otot. Kerusakan yang terjadi pada struktur myofilaments akan menyebabkan gangguan nyeri pada otot berupa sensasi ketegangan (tightness) yang menyebabkan keterbatasan gerak otot. ${ }^{29}$ 


\section{SIMPULAN}

Simpulan yang dapat ditarik berdasarkan hasil dan diskusi yang telah dibahas yaitu semakin lama durasi duduk semakin rendah fleksibilitas otot hamstringnya begitu pula semakin tiinggi skor REBA semakin rendah skor fleksibilitas otot hamstring pada pegawai kantor.

\section{DAFTAR PUSTAKA}

1. Agustin, \& Daniati. 2013. Pengaruh Pemberian Autostretching Terhadap Fleksibilitas Otot hamstring Pada Kasus Tightness Hamstring.

2. Alter, J., \& Michael. 2004. Science of Flexibility. Englend: Human Kinetics Publishers.

3. Andini, F. 2015. Risk Factors Of Low Back Pain In Workers. Volume 4 Nomor 1.

4. Anshar, \& sudaryanto. 2011. Biomekanik Osteokinematika dan Arthokinematika Kementrian Kesehatan RI.

5. Aras, D., Ahmad, H., \& Ahmad, A. 2014. Palpasi Anatomi Otot Skeletal. Makasar: Physiocare And Publishing.

6. Babu, V., Akalwadi, A., Kumar, S., \& Una. 2015. Immediate Effect Of Neurodynamic Sliding Technique Versus Mulligan Bent Leg Raise Technique On Hamstring Flexibility In Asymptomatic Individuals. Vol 2

7. Effendy, S. 2017. Hubungan aktifitas fisik terhadap kejadian obesitas berdasarkan body fat percentage di dusun tanjung desa banjaroyo kalibawang kulon progo Yogyakarta.

8. Evangelidis, \& Pavlos, E. 2015. Hamstrings muscle anatomy and function, and implications for strain injury.

9. Fatima, G., Basharat, A., \& Qamar, M. M. 2017. Extended sitting can cause hamstring tightness.

10. Garnis, R. 2015. Kualitas Diet dan Aktivitas Fisik pada Remaja Obesitas.

11. Gummerson. 2000. Stretching and Flexibility.

12. Guyton, A., \& Hall. 1997. Buku Ajar Fisiologi Kedokteran. Jakarta: EGC.

13. E, L. D. 2016. Fisiologi dan Pengukuran Kerja. Fakultas Teknologi Industri. SkripsiUniversitas Islam Indonesia.

14. Ilyas, F. R. 2016. Hubungan Antara Fleksibilitas Dengan Delayed Onset Muscle Soreness Pada Mahasiswa Ekstrakurikuler Karate.

15. Kisner, C., \& Colby , A. L. 2007. Therapeutic Exercise: Foundations and Techniques

16. koulouris, G., connell, d., \& Franzcr. 2005. Hamstring Muscle Complex: An Imaging Review.

17. Moore, K. L., Dalley II, A. F., R, A. M., \& Agur. 2013. Clinically Oriented Anatomy. In D. Hartono, Anatomi Beririentasi Klinis (Vol. 5). Inggris: Erlangga.

18. Murti, O. S. 2016. Perbedaan Pengaruh Peningkatan Fleksibilitas Back Muscle.

19. Nugraha, D. A. 2014. Perbedaan Tingkat Fleksibilitas Laki-Laki dan Perempuan Mahasiswa Fakultas Kedokteran.

20. Pramasita Novi Aldiani Perbedaan Pengaruh Neurodynamic Sliding Technique dan Muligan Bent Leg Raise Technique Terhadap Fleksibilitas Hamstring Pada Hamstring Tightness [Journal] // Naskah Publikasi . - 2016.

21. Panero, Julius, \& Zelnik, M. 2003. Dimensi Manusia \& Ruang Interior.

22. Parjoto, \& Slamet. 2007. Pentingnya Memahami Sikap Tubuh Dalam Kehidupan.

23. Riskesdas. 2013. Riset Kesehatan Dasar.

24. Schuenke, M., Schulte, E., Schumacher, U., Ross, L., \& Lamperti, E. 2010. General Anatomy and Musculoskeletal System (Thieme Atlas of Anatomy).

25. Siswanto, Susila, \& Suyanto. 2013. Metodologi Kedokteran dan Kesehatan. Karangkajen Yogyakarta: Bursa IImu.

26. Straker, L. 2000. An overview of manual handling injury statistic in Western Australia.

27. Syukur, A. 2015. Pengaruh Latihan Active Isolated Stretching Dan Auto Stretching Dalam Meningkatkan Fleksibilitas Otot hamstring Pada Penjahit Di Desa Kaliprau.

28. Tarwaka, Bakri, S. H., \& Sudiajeng, L. 2004. Ergonomi Untuk Keselamatan Kerja Dan Produktivitas. Surakarta: UNIBA PRESS Universitas Islam Batik Surakarta.

29. Jan Dommerholt. 2011 Dry needling peripheral and central considerations. Journal of manual \& manipulative therapy

30. Tristiana, A. 2017. Hubungan aktivitas fisik dengan kejadian disminore primer pada santri di pondok pesantri $X$ di kabupaten Bogor.

31. Usman, R. A. 2016. Perbandingan Fleksibilitas Punggung Bawah Dengan Metode Sit And Reach Pada Siswa Obesitas Dan Non Obesitas.

32. Waqas, M. S., Mazher, A., Hussain, s., \& Mahmood, S. 2016. Frequency of reduced hamstring fexibility in prolong sitting (6-8 hours) among office workers (Vols. (2):77-80 ). Pakistan: Journal of Riphah College of Rehabilitation Sciences.

33. Wiranti, M. 2013. Pengaruh Pemberian Muscle Energi Technique (MET) Terhadap Fleksibilitas Otot hamstring Pada Kasus Tightness Hamstring . 